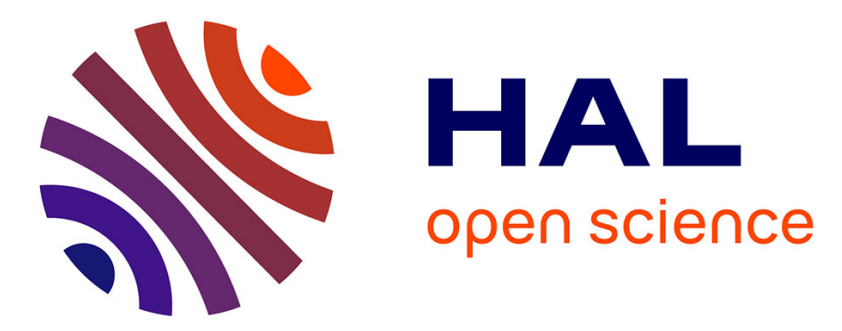

\title{
Multiscale analysis of thermal degradation of polyamide 6,6 - Influence of temperature on oxygen diffusion-limited oxidation profiles
}

M. Pliquet, M. Rapeaux, F. Delange, D. Bourgogne, J.L. Gardette, S. Therias, P.O. Bussiere

\section{To cite this version:}

M. Pliquet, M. Rapeaux, F. Delange, D. Bourgogne, J.L. Gardette, et al.. Multiscale analysis of thermal degradation of polyamide 6,6 - Influence of temperature on oxygen diffusion-limited oxidation profiles. Polymer Degradation and Stability, 2021, 192, pp.109695. 10.1016/j.polymdegradstab.2021.109695 . hal-03401853

\author{
HAL Id: hal-03401853 \\ https://hal.uca.fr/hal-03401853
}

Submitted on 12 Nov 2021

HAL is a multi-disciplinary open access archive for the deposit and dissemination of scientific research documents, whether they are published or not. The documents may come from teaching and research institutions in France or abroad, or from public or private research centers.
L'archive ouverte pluridisciplinaire HAL, est destinée au dépôt et à la diffusion de documents scientifiques de niveau recherche, publiés ou non, émanant des établissements d'enseignement et de recherche français ou étrangers, des laboratoires publics ou privés.

\section{(c)(1)}

Distributed under a Creative Commons Attribution| 4.0 International License 


\section{Multiscale analysis of thermal degradation of polyamide 6,6 - Influence of temperature on oxygen diffusion-limited oxidation profiles.}

M. Pliquet ${ }^{\mathrm{a}, \mathrm{b}}$, M. Rapeaux ${ }^{\mathrm{b}}$, F. Delange ${ }^{\mathrm{b}}$, D. Bourgogne ${ }^{\mathrm{a}}$, J.L. Gardette ${ }^{\mathrm{a}}, \mathrm{S}$. Therias $^{\text {a }}$, P.O. Bussiere ${ }^{\mathrm{a}^{*}}$

${ }^{\text {a } U n i v e r s i t e ́ ~ C l e r m o n t ~ A u v e r g n e, ~ C l e r m o n t ~ A u v e r g n e ~ I N P, ~ C N R S, ~ I C C F ~, ~ F-63000 ~ C l e r m o n t-~}$ Ferrand, France

${ }^{\mathrm{b}}$ Schneider Electric, Site Electropôle, 31 rue Pierre Mendès France, F-38320 Eybens, France.

*Corresponding authors:

I.C.C.F, UMR 6296 - Institut de Chimie de Clermont-Ferrand, Université Clermont Auvergne

- CNRS - SIGMA Clermont Campus des Cézeaux - 24, avenue Blaise Pascal - TSA 60026 CS 6002663178 Aubière Cedex, France. E-mail address: pierre-olivier.bussiere@sigmaclermont.fr (P.O. Bussiere). 


\begin{abstract}
This paper is devoted to the impact of oxygen diffusion on thermal ageing of PA-6,6. Samples were subjected to ageing in air at temperatures ranging from $140{ }^{\circ} \mathrm{C}$ to $200{ }^{\circ} \mathrm{C}$ for different times. Depth profiling methods using AFM measurements were developed to characterise the heterogeneity of the thermal and mechanical properties of the oxidised polymer. A comparison of the results obtained with micro-FTIR profiles was performed to correlate the chemical and physical changes induced by oxidation (i.e., from molecular to macroscopic scales). As a result of diffusion-limited oxidation (DLO), it was shown that polymer oxidised much faster at the surface than in the bulk.
\end{abstract}

KEYWORDS: Polyamide 6,6, Thermo-oxidation, profile, AFM (atomic force microscopy), diffusion-limited oxidation (DLO) 


\section{Introduction}

Aliphatic polyamides are engineering polymers. They can be used in various fields, such as textiles, automotive, and electrical insulation. Certain applications require high-temperature exposure, which can reduce the performance of the material during its service life. The thermal oxidation of polyamides in the bulk is a widely studied process since polyamides are commonly used in applications that require long-term/high-temperature exposure. [1][5] It is known that polyamide 6,6 oxidation is a chain radical mechanism that starts with the removal of the most labile hydrogen in the $\alpha$-position to the amide nitrogen. Regarding the basic autoxidation scheme, hydroperoxides are the first oxidative products. [6][7] The decomposition of $\alpha$-amino hydroperoxides then leads to the formation of imides, carboxylic acids, amines and aldehydes. [8][10] Changes in the chemical structure can cause a degradation of the macromolecular architecture [11][12] and microstructure [13][14] and a loss of the functional properties. [15][16] Beyond chemical changes, oxygen permeation can also spatially affect the degradation of polymer materials. [17][22] When the oxygen consumption rate is higher than the oxygen permeation, oxidation then becomes limited by oxygen diffusion (DLO). [23][24] As a result, an oxidation profile across the material thickness develops and is indicative of heterogeneous oxidation. Oxygen is primarily consumed during surface oxidation and thus does not penetrate deeper layers in the material. Various experimental techniques are employed to investigate the oxidation heterogeneity in polymers, including infrared microspectroscopy [25][27], chemiluminescence [28][30] and oxygen absorption measurements. [18] These techniques allow for the characterisation of chemical changes induced by oxidation. Novel analytical methods are required to characterise degradation at the upper levels. Atomic force microscopy (AFM) is an advanced technique that determines material properties with nanometric precision. In this study, AFM is used to measure thermal and mechanical properties. Recent studies using AFM to characterise the 
changes in material properties due to ageing have suggested that it can be an efficient tool. $[31][35]$

In this paper, oxidation profiles of PA 6,6 thick samples were determined using different techniques that characterise the material changes from molecular to macroscopic scales. The aim was to determine pertinent degradation probes to validate the multiscale approach protocol.

\section{Experimental methods}

\subsection{Materials}

The experimental raw material was commercial grade polyamide 6,6 supplied by DuPont ${ }^{\mathrm{TM}}$ $\left(\right.$ Zytel $\left.^{\circledR} 101 \mathrm{~L}\right)$. The samples were injection moulded directly into plates $(80 \times 80 \mathrm{~mm})$ with a thickness of $1.5 \mathrm{~mm}$. After moulding, the materials were kept in specific packs to prevent any moisture uptake before thermal ageing.

\subsection{Oven ageing}

The thermo-oxidative ageing was carried out in a forced air venting oven (Memmert UF30) at temperatures between $140{ }^{\circ} \mathrm{C}$ and $200{ }^{\circ} \mathrm{C}$. The samples were collected after different time intervals up to $3000 \mathrm{~h}$. A minimum of three samples were prepared and characterised per ageing time to ensure reproducibility of the measurements.

\subsection{Characterisation techniques}

\subsubsection{FTIR microscopy}


Infrared microspectroscopy was used to measure the oxidation profiles on the PA 6,6 plates. The specimens were $20 \mu$ m-thick films from the cross section of oxidised PA 6,6 that were cut using a LEICA RM2165 microtome with tungsten carbide blades. The micro-FTIR analyses were performed on a Nicolet 6700 spectroscope coupled with a Nicolet continu FTIR microscope (Thermo Scientific). The dimensions of the infrared beam were a $30 \mu \mathrm{m}$ length and $100 \mu \mathrm{m}$ height. The infrared beam scanned the cross-sectional film every $20 \mu \mathrm{m}$. The spectra were collected for 128 scans at a resolution of $4 \mathrm{~cm}^{-1}$.

\subsubsection{AFM nanoscale thermal analysis (VITA)}

Changes in the melting temperature with ageing were followed by an AFM nanoscale thermal analysis system. Measurements were performed on the cross section of oxidised PA 6,6 to determine the melting temperature profile. The technique used a thermal probe to heat a small region on the sample slice and locally measure its thermal properties, such as the glass transition temperature or melting temperature. During the measurement, the probe was fixed at a specific thickness. When the probe temperature is increased, the sample heats and undergoes progressive thermal expansion. With the expansion, the probe pushes up, which leads to a positive cantilever deflection. At a transition temperature (such as $\mathrm{T}_{\mathrm{m}}$ or $\mathrm{T}_{\mathrm{g}}$ ), a material softens, allowing the probe to penetrate into the sample. The penetration causes a decrease in the deflection of the cantilever. To determine the transition temperature, the deflection signal is plotted as a function of the probe temperature. The maximum of the curve corresponds to this transition temperature.

The VITA system contained a probe (tip + cantilever) connected to an electric circuit. The probe was heated by the Joule effect by applying an electric current on the system. A calibration was mandatory to correlate the applied tension to the corresponding temperature. The probe was calibrated with three standard polymers with known melting temperatures: 
polycaprolactone $\left(\mathrm{T}_{\mathrm{m}}=55^{\circ} \mathrm{C}\right)$, polyethylene $\left(\mathrm{T}_{\mathrm{m}}=116^{\circ} \mathrm{C}\right)$ and polyethylene terephthalate $\left(\mathrm{T}_{\mathrm{m}}=235^{\circ} \mathrm{C}\right)$. The spring constant of the VITA probe was between $0.5 \mathrm{~N} / \mathrm{m}$ and $3 \mathrm{~N} / \mathrm{m}$, and its cantilever was $200 \mu \mathrm{m}$ long.

Measurements were performed on the profiles of non-aged and aged PA samples to determine changes in the thermal properties with thermo-oxidative ageing. [36] After cross section cutting, a mapping of the melting temperature variation was performed between depths of 0 and $350 \mu \mathrm{m}$. For each depth, nine measurements were performed. A distance of $15 \mu \mathrm{m}$ was fixed between two measurements points to prevent the thermal expansion effect. During these experiments, the probe was heated from $30{ }^{\circ} \mathrm{C}$ to $350{ }^{\circ} \mathrm{C}$ at a heating rate of $5{ }^{\circ} \mathrm{C} / \mathrm{s}$. AFM images of the zone under study were collected before and after testing to observe the shape and the dimensions of the hole left behind the probe during melting.

\subsubsection{AFM nanoscale mechanical measurements}

The PeakForce QNM mode in AFM was used to determine mechanical properties, such as the modulus, adhesion, roughness and deformation, with a nanometric resolution. The AFM measurements were performed with a Bruker Multimode 8 model equipped with a Nanoscope 9.20 in tapping mode. The sample was placed on a piezoelectric, which assured XYZ displacement. Topographic images were collected with a probe on silicon from Bruker. The RTESPA 300-30 model was used that had a curvature radius of $30 \mathrm{~nm}$ and a spring constant near $40 \mathrm{~N} / \mathrm{m}$. The topographic images were processed to determine the roughness $\left(\mathrm{R}_{\mathrm{q}}\right)$ according to equation 1:

$$
\mathrm{R}_{\mathrm{q}}=\sqrt{\frac{\sum\left(\mathrm{z}_{\mathrm{t}}\right)^{2}}{\mathrm{~N}}}
$$

where $\mathrm{z}_{\mathrm{t}}$ is the current height value and $\mathrm{N}$ is the number of points within the considered area. While obtaining the topographic images, force curves were collected at every pixel of the 
image. The analysis of the force curve data with the Nanoscope 9.20 software provided the mechanical properties. For the study, the stiffness was tracked by the reduced Young's modulus $\mathrm{E}^{*}$ obtained in the DMT modulus images. The model used to calculate $\mathrm{E}^{*}$ was provided by Derjaguin et al. [37]

Measurements were performed on cross-sections of PA 6,6 samples in VITA mode to determine the mechanical properties in the bulk of the material. Images with dimensions of 5 $\mu \mathrm{m} \times 5 \mu \mathrm{m}$ at a scan rate of $0,5 \mathrm{~Hz}$ with 512 scan lines were captured. The mapping was conducted by collecting images between depths of 0 and $325 \mu \mathrm{m}$. At each depth, five areas were measured, and 3 images were collected in each measurement area. For probe calibration, the sample must be clean and hard with a known mechanical modulus. The probe was calibrated with silicon $(\mathrm{E}=130-185 \mathrm{GPa})$. A quantitative measurement of the reduced Young modulus also requires a calibration of the cantilever spring constant and piezoelectric scanner movement. As a polymer surface is rarely flat and the tip vertex geometry is not exactly spherical, this can induce calculation errors not accounted for in the Derjaguin-MullerToporov (DMT) model used to determine the mechanical module [38]. This is why the study was limited to the measurement of the relative variation of the stiffness. [39][40] 


\section{Results and discussion}

\subsection{Chemical structure}

Infrared microspectroscopy was used to investigate the distribution of the chemical changes in the thickness of PA 6,6 plates induced by thermal degradation and determine the influence of temperature on this distribution. Samples of $1500 \mu \mathrm{m}$ thickness were aged in thermo-oxidative conditions for different times and temperatures. After ageing, the distribution of the oxidation products through the thickness of samples aged at $140{ }^{\circ} \mathrm{C}, 160{ }^{\circ} \mathrm{C}, 180{ }^{\circ} \mathrm{C}$ and $200{ }^{\circ} \mathrm{C}$ were monitored. The distribution of the oxidation products was recorded at $1734 \mathrm{~cm}^{-1}$ which reflects the formation of imides. [41] The oxidation profiles which were obtained are displayed in Fig. 1 and represented in differential values according to the following equation:

$$
\Delta \mathrm{A}=\mathrm{A}_{\mathrm{t}}-\mathrm{A}_{\mathrm{ref}}
$$

with $\mathrm{A}$ the imide absorbance. $\mathrm{A}_{\text {ref }}$ corresponds to the absorbance measured in the middle of the unaged thick sample and $A_{t}$ the absorbance at a specific thickness. 

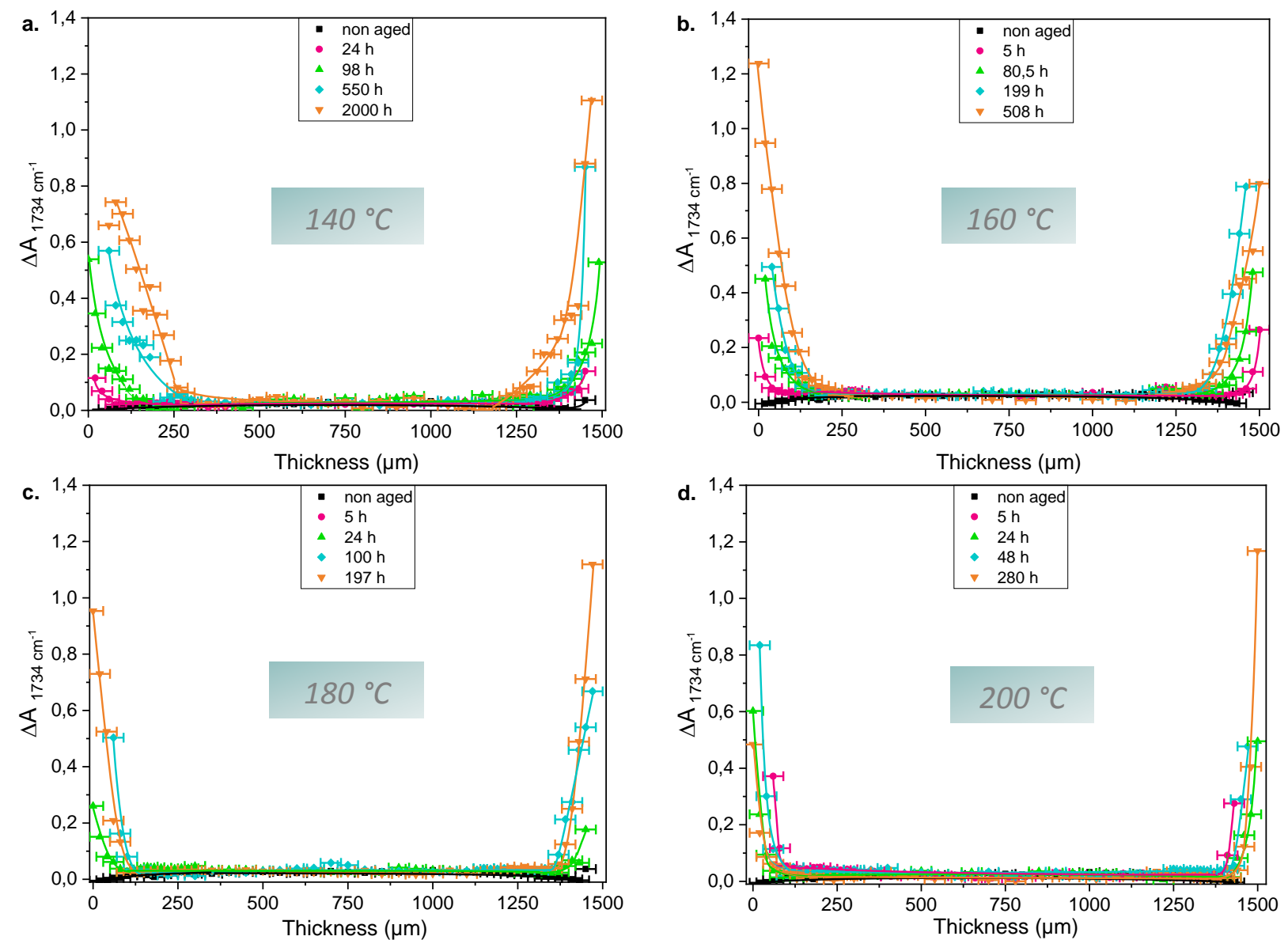

Fig. 1 Oxidation depth profiles of samples aged in thermo-oxidation for different times at 140

$$
{ }^{\circ} \mathrm{C}(\mathrm{a}), 160{ }^{\circ} \mathrm{C}(\mathrm{b}), 180{ }^{\circ} \mathrm{C}(\mathrm{c}) \text { and } 200{ }^{\circ} \mathrm{C}(\mathrm{d}) \text {. }
$$

The curves in Fig. 1 show an oxidation depth profile that reflects a diffusion-controlled oxidation process (DLO). [42] The aged samples present a typical skin-core oxidation profile with the formation of oxidation products at the surface of the sample while the core remains unchanged. The profiles are symmetric with the formation of imides at the surface, which increases progressively over time. The profile is marked, and the oxidation becomes more superficial as the ageing temperature increases. The oxidation depth can be defined as the distance from the surface at which no oxidation products are formed. [43] In Table. 1, the oxidation depth is indicated for when the absorbance at the surface exceeds 1 for each exposure temperature. 
Table. 1 Total oxidation depth for each ageing temperature

\begin{tabular}{|c|c|}
\hline Ageing temperature $\left({ }^{\circ} \mathrm{C}\right)$ & Total oxidation depth $(\mu \mathrm{m})$ \\
\hline 140 & 560 \\
\hline 160 & 360 \\
\hline 180 & 270 \\
\hline 200 & 200 \\
\hline
\end{tabular}

The data in Table. 1 clearly indicate that the thickness of the oxidised layer is temperature dependent. A decrease in oxidation depth is observed when the ageing temperature rises, which is in accordance with the results in the literature. [42][44][45] The increase in temperature and ageing time enhances the skin-core oxidation profile. The development of diffusion-limited oxidation profiles is the result of competition between the oxidation rate and oxygen diffusion. [46][47] Consequently, as the oxidation rate increases faster than the oxygen diffusion with temperature, one can suggest that the total amount of oxygen is consumed at the surface of polymer plates and then cannot diffuse deeply in the bulk when the ageing temperature increases.

\subsection{Crystallinity}

Infrared spectroscopy has also been used to investigate the microstructure properties of a polymer, such as the crystallinity and crystalline morphology. [48] In the literature, various IR bands have been assigned to the crystalline and amorphous phases in PAs. [49][50] The bands at 906,936 and $1200 \mathrm{~cm}^{-1}$ are attributed to the crystalline phase, while the bands at 924 and $1136 \mathrm{~cm}^{-1}$ are assigned to the amorphous phase. [51][56] The bands at 936 and $924 \mathrm{~cm}^{-1}$ that correspond to the $\mathrm{C}-\mathrm{C}=\mathrm{O}$ stretching in the respective crystalline and amorphous phases 
overlap. A deconvolution is necessary to distinguish the absorbance of the two bands. For simplicity, the bands at 906 (am) and $1136 \mathrm{~cm}^{-1}$ (cry), which are directly accessible in IR spectra, were chosen to determine the amount of crystalline material. The crystallinity ratio determined by FTIR spectrophotometry was calculated according to the following equation:

$$
\chi_{C}=\frac{A_{\text {cry }}}{A_{\text {cry }}+\alpha \times A_{\text {am }}}
$$

where $\mathrm{A}_{\text {cry }}$ and $\mathrm{A}_{\mathrm{am}}$ are the absorbance of crystalline and amorphous bands, respectively, and $\alpha$ is the ratio between both molar extinction coefficients:

$$
\alpha=\frac{\varepsilon_{c r y}}{\varepsilon_{a m}}
$$

According to the literature, the coefficient $\alpha$ is equal to 0,57 for the selected band ratio. [57] The crystallinity as a function of the thickness were determined before ageing and after ageing for $100 \mathrm{~h}$ at $180{ }^{\circ} \mathrm{C}$. The resulting crystallinity depth profiles are displayed in Fig. 2 .

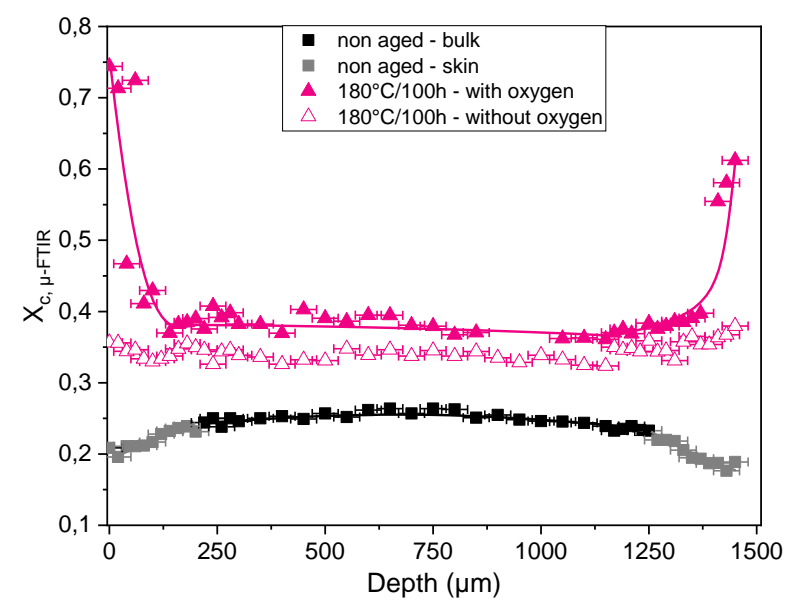

Fig. 2 Crystallinity depth profiles determined by FTIR microspectroscopy for a sample before ageing ( $\square)$ and for two samples aged at $180{ }^{\circ} \mathrm{C}$ for $100 \mathrm{~h}$ with $(\Delta)$ and without oxygen $(\Delta)$.

Interestingly, it should be noted that the relative crystallinity determined by infrared spectroscopy in the bulk $(\approx 27 \%)$ for the sample before ageing is close to the degree of 
crystallinity measured by DSC $(\approx 30 \%)$ [58], which confirms the relevance of infrared to determine the crystallinity.

From the curves presented in Fig. 2 , we can notice that the crystallinity amount is lower $(\approx 19$ $\%$ ) in the first $200 \mu \mathrm{m}$ than in the core $(\approx 27 \%)$ for the PA 6,6 sample before ageing. This may result from the processing of the samples. During injection moulding, crystallisation occurs during cooling of the melt. The skin parts that are directly in contact with the cold mould surfaces are quickly cooled. Many studies have investigated the influence of thermal history on the skin/core morphology. [59][64] Based on the literature, it is assumed that the core cooling rate ranges from approximately 400 to $600 \mathrm{~K} \cdot \mathrm{s}^{-1}$ and is slower than that in the skin. [60][62][65] During slow cooling, the chains have sufficient time to arrange into crystals. In comparison, the rapid cooling in the skin inhibits the development of crystals and spherulites, which is reflected in a lower crystallinity ratio than that of the core. This result can directly explain why the mechanical properties of this kind of polymer present before aging a such strong difference from the surface to the bulk and why it is so difficult to directly compare directly hardness measurements (i.e. surface analysis) to tensile test.

After thermal ageing in air, a significant increase in the crystallinity can be seen over the entire thickness of the sample thermo-oxidised at $180{ }^{\circ} \mathrm{C}$ for $100 \mathrm{~h}$. In addition, the crystallinity profile of the thermo-oxidised sample is heterogeneous; in other words, the crystallinity of the surface is significantly higher than that of the core. The crystallinity increase was previously observed in the bulk by DSC [66] and ascribed to chain scissions that release chain fragments that are able to integrate into the crystalline phase by chemicrystallisation or to reorganise in new crystals. [67] The crystallinity profile evolves from the surface up to $200 \mu \mathrm{m}$ towards the core and then stays at approximately $40 \%$. The profile shape and depth are comparable to the infrared profile obtained by monitoring the 
oxidation products. However, while no oxidation products are detected in the core of the material due to the DLO effect, an increase in the crystallinity from $27 \%$ to $40 \%$ occurs simultaneously. This significant increase in the crystallinity in few hours of aging can also explain why, in our previous paper [58], we have seen a drop in the $\tan \delta$ peak maximum, which indicated a loss in molecular mobility in the first hours of aging when the chainscissions mechanism was not the major phenomenon.

To explain this behaviour, we measured crystallinity after ageing for the same time $(100 \mathrm{~h})$ but in the absence of oxygen. The results obtained show a homogeneous crystallinity of approximately $37 \%$ over the entire thickness, which is higher than the crystallinity measured in the sample before ageing. The polymer is quenched during moulding as it is cooled rapidly, which results in the development of an unstable crystalline morphology. Submitting the sample to a temperature above its glass transition temperature $\left(\mathrm{Tg}=65{ }^{\circ} \mathrm{C}\right)$ allows the macromolecular chains to rearrange and crystallise, which improves the order in the crystalline phase and increases the crystallinity. [68] This also occurs when the sample is subjected to oxidation, which explains the increase in the crystallinity in the bulk, despite no oxidation occurring as a result of oxygen depletion.

The different semi-crystalline morphologies in the various regions of the moulded sample can have an impact on macroscopic properties, such as the mechanical or optical properties. [69][70] These results permit also to better understand the consequences of the oxidation and to definitely separate the consequences of an oxidation process versus an annealing process. This crystallinity profiles in presence or in absence of oxygen also lead to a new view on the hardness evolution that we have presented in our previous paper. The important increase of this parameter and especially in the first aging time should also be linked to the annealing 
process that takes place at the polymer surface and not only to the chemicristallisation process.

\subsection{AFM nanoscale thermal analysis}

In addition to the spectroscopic changes presented above, macroscopic modifications also occur during thermo-oxidative ageing of samples. Thermal analysis, such as differential scanning calorimetry (DSC) and dynamic mechanical analysis (DMA), are commonly used techniques to characterise the transition temperatures of a polymeric material. However, their main drawback is that they give only an average result because these techniques are not able to conduct a local investigation (i.e., they conduct bulk measurements). In contrast, a mapping of the properties (thermal analysis and/or mechanical) at nanometric scale can be performed using AFM. This new technique allows determining the variation of a property not only from the surface to the core of the sample as many depth profiling techniques, but also in a particular area of interest. Before AFM measurements pictures of the area were recorded (SI Figure 10) in order to see if the mapping area presents cracks, roughness... that could completely modify the obtained results.

AFM thermal analysis $\left(\right.$ VITA $\left.^{(}\right)$is a technology that allows a local determination of thermal properties, such as the melting point or glass transition temperature. [71][73] To collect the mapping results, the melting temperature was chosen to evaluate changes in the microstructure with thermo-oxidative ageing. First, thermal mapping was carried out on PA 6,6 before ageing. (Fig. 3) 


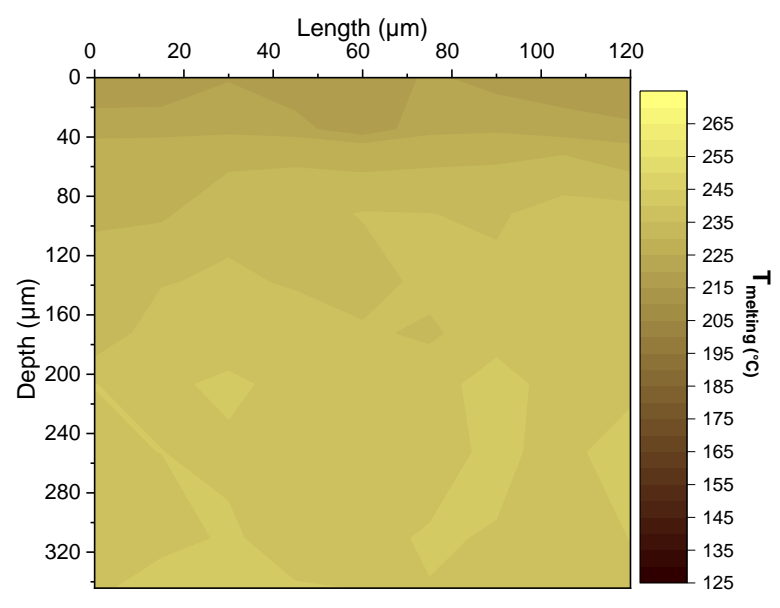

Fig. 3 Melting temperature mapping of non-aged PA 6,6.

From the map presented in Fig. 3, we notice that the melting temperature in the first $50 \mu \mathrm{m}$ is lower than that in the core for the PA 6,6 sample before ageing. This result agrees with the crystallinity results presented in Fig. 2 and highlights the skin effect.

Mapping was also performed on two samples aged at $140{ }^{\circ} \mathrm{C}$ for $2000 \mathrm{~h}$ and $180{ }^{\circ} \mathrm{C}$ for $197 \mathrm{~h}$, and the obtained results are presented in Fig. 4. These ageing times were selected because they correspond to the maximum thickness of the oxidised layer for each of the temperatures selected.
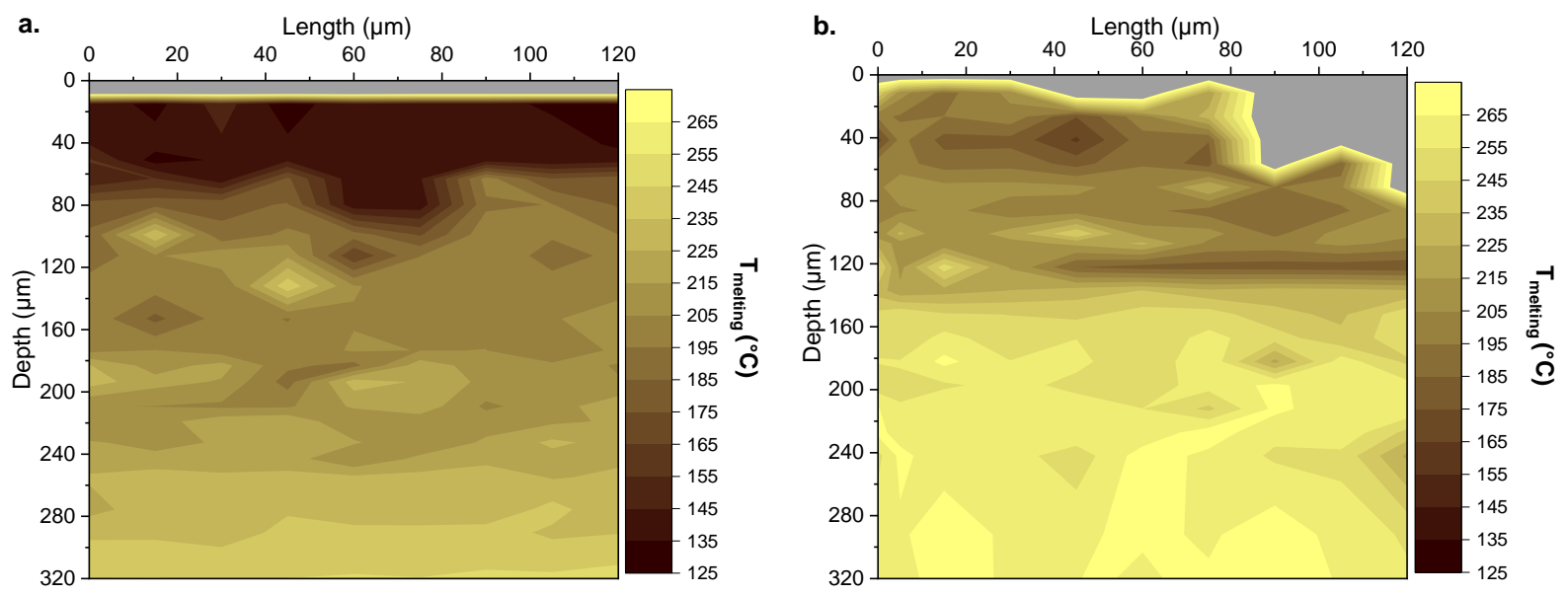

Fig. 4. Melting temperature mapping of samples thermo-oxidised at (a) $140{ }^{\circ} \mathrm{C}$ for $2000 \mathrm{~h}$ and (b) $180{ }^{\circ} \mathrm{C}$ for $197 \mathrm{~h}$. 
Changes in the melting temperature are observed from the surface to the core (until $320 \mu \mathrm{m}$ is reached). With thermal ageing, the melting temperature ranges from $125{ }^{\circ} \mathrm{C}$ to $275{ }^{\circ} \mathrm{C}$. The hatched area corresponds to a region where no melting is observed. It is important to specify that the melting temperature measured by AFM corresponds to the onset of the melting peak measured by DSC. Indeed, the AFM probe deflects as soon as the material starts to melt. In Fig. 4a, we observe that the melting temperature of the sample aged at $140{ }^{\circ} \mathrm{C}$ gradually evolves across the whole profile. The melting temperature decreases as one approaches the surface. In the first $80 \mu \mathrm{m}$, the melting temperature is approximately $125^{\circ} \mathrm{C}$ and $145^{\circ} \mathrm{C}$. These findings are relevant to our previous results measured by DSC [58], where we observed a large distribution of the melting peak towards lower temperatures with thermal ageing. For the sample aged at $180^{\circ} \mathrm{C}$ presented in Fig. $4 \mathrm{~b}$, the melting temperature gradient extends from the surface to a depth of $170 \mu \mathrm{m}$. From there, the melting temperature remains at $265^{\circ} \mathrm{C}$ and does not change. The thermal property profile at $140{ }^{\circ} \mathrm{C}$ is deeper and more progressive than the profile determined at $180{ }^{\circ} \mathrm{C}$, which is consistent with the results previously obtained by infrared microspectrometry. The melting temperature at the surface and near the surface could not be determined despite heating up to $350{ }^{\circ} \mathrm{C}$ (hatched area). The lack of melting in this particularly degraded area may be caused by crosslinking and/or carbonisation of the surface with thermal ageing. Authors that characterised ageing by SEC or rheology have shown that thermo-oxidation mainly causes chain scissions [12][13], but a crosslinking process cannot be excluded and has been observed for samples that underwent advanced ageing. [74] 


\subsection{AFM nanoscale mechanical properties}

AFM in Peak Force QNM mode was employed to characterise the mechanical properties at the surface and in the bulk of the polymeric materials. [75][78] This AFM mode gives access to the DMT modulus, which can be likened to the reduced Young's modulus. [38] Mapping was carried out on the same two samples as for those analysed with AFM thermal analysis but in a different area because this analysis is destructive. The results of the DMT modulus mapping are presented in Fig. 5.
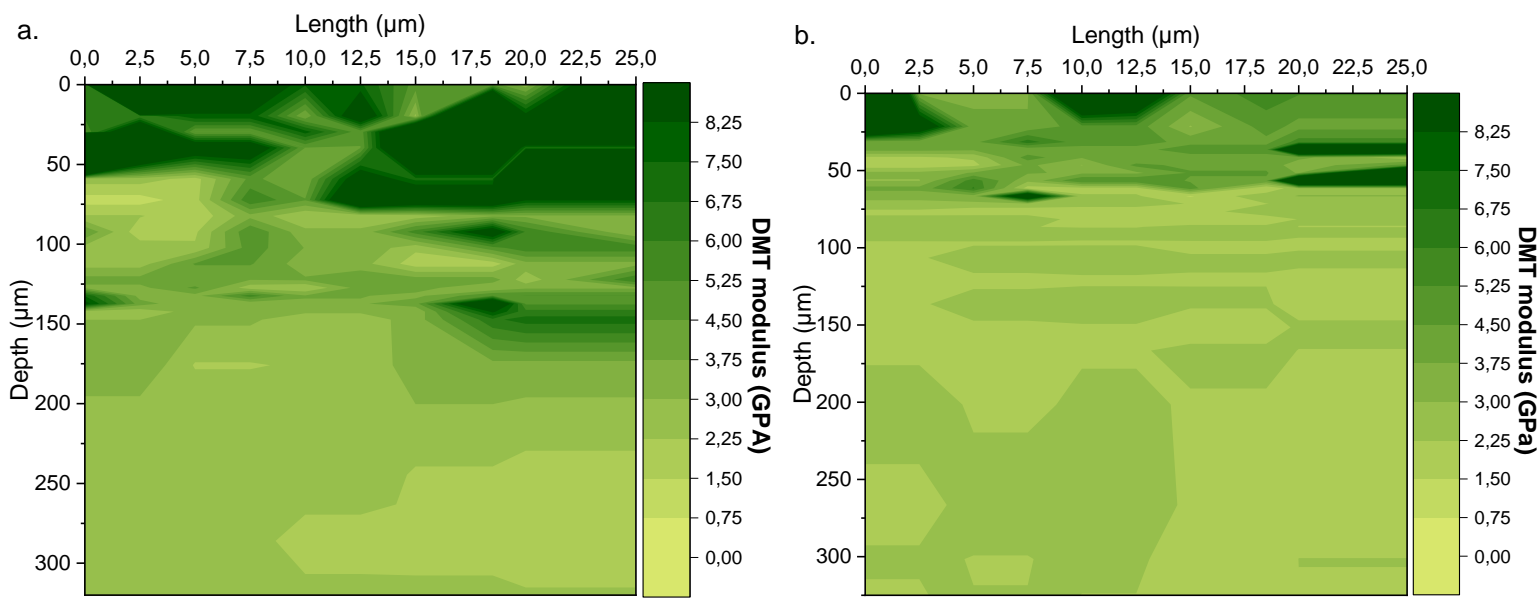

Fig. 5 Stiffness mapping of samples thermo-oxidised at (a) $140{ }^{\circ} \mathrm{C}$ for $2000 \mathrm{~h}$ and (b) $180{ }^{\circ} \mathrm{C}$ for $197 \mathrm{~h}$.

A large distribution of the DMT modulus from the surface to the core can be seen in both samples. The DMT modulus varies between 1,5 and 2,5 GPa in the core and can increase to $10 \mathrm{GPa}$ at the surface. The effect of thermal oxidation on the mechanical properties can be seen up to a depth of $200 \mu \mathrm{m}$ in the sample aged at $140{ }^{\circ} \mathrm{C}$, while it remains very superficial in the sample aged at $180{ }^{\circ} \mathrm{C}$. One can also notice that the modulus mapping does not show like in the case of mapping of melting temperature a blank zone in the first micrometers (surface). This zone corresponds to a degraded area with an important stiffness that can be linked to a crosslinking of the surface with thermal ageing. Authors that characterised ageing 
by SEC or rheology have shown that thermo-oxidation can also lead to a crosslinking process and this has been observed for samples that underwent advanced ageing. [74] Thus, this experiment allows us not only to specifically separate the crosslinking reactions from the chain scission mechanism but also to identify areas where one of the reactions is predominant over the other. 


\subsection{Multi-scales correlations}

In a previous paper, we proposed a multiscale approach to characterise the PA 6,6 thermal degradation. [58] We showed that following the variations in the intensity of the band at 3080 $\mathrm{cm}^{-1}$, assigned to the overtone of the amide II band, was a relevant chemical probe to correlate changes in the chemical structure with the resulting modifications of the microstructure and loss of functional properties. The variations in absorbance at $3080 \mathrm{~cm}^{-1}$ fit well with the changes in the crystallinity, molar mass and microhardness. In the current study, the variation in the absorbance at $3080 \mathrm{~cm}^{-1}$ as a function of the distance from the outer surface was also investigated. Fig. 6 shows the variations in absorbance at $3080 \mathrm{~cm}^{-1}$ through the thickness of thick samples aged for various times at $140{ }^{\circ} \mathrm{C}$.

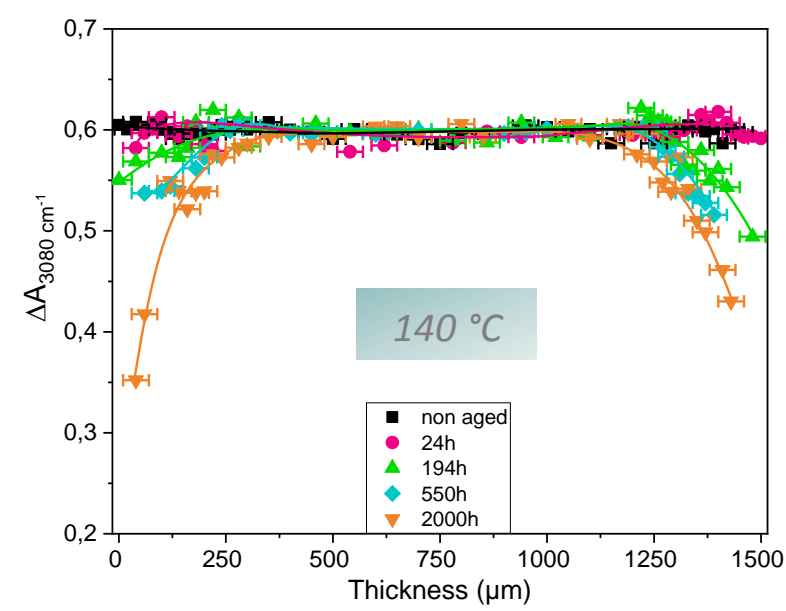

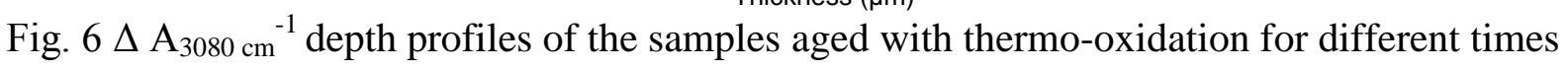
at $140{ }^{\circ} \mathrm{C}$. 


\section{Fig. 6 shows a similar skin-core profile as those reported above, with a}

decrease in the absorbance from the core to the surface. The drop in the amide absorbance reflects that oxidation occurs.

The absorbance at $3080 \mathrm{~cm}^{-1}$ may be correlated to the modifications of other properties of the polymer to establish a multiscale characterisation of the profiles after ageing. Fig. 7 displays the thermo-oxidation profiles determined by AFM thermal mode and micro-FTIR in the first $400 \mu \mathrm{m}$ of a thick sample $(1.5 \mathrm{~mm})$ aged at $180^{\circ} \mathrm{C}$ for $197 \mathrm{~h}$.

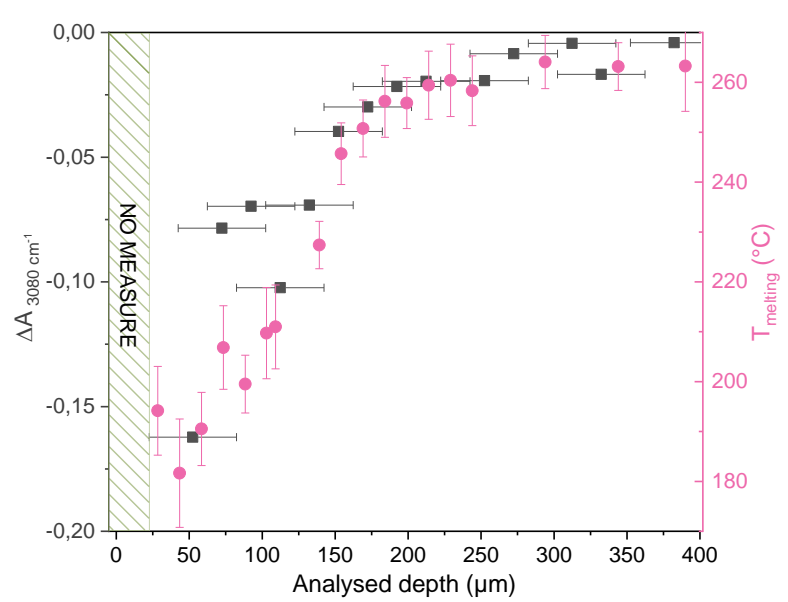

Fig. 7 Thermo-oxidation profile of a PA 6,6 sample measured by micro-FTIR ( $(-)$ and AFM -

$$
\operatorname{VITA}(\bullet) \text { after } 197 \mathrm{~h} \text { of ageing at } 180^{\circ} \mathrm{C} \text {. }
$$

As shown above in Fig. 7, the loss of the amide bond is only observable in the first 200 microns and is more apparent as the surface is reached. Correspondingly, in the first 200 microns, the melting temperature measured using AFM nanoscale thermal analysis is decreasing. According to the oxidation mechanism, chain scissions occur at the C-N bond of the amide, resulting in the formation of aldehydes, carboxylic acids and primary amides as oxidation products. [79][80] The resulting crystallites composed of chain fragments are small and thus tend to melt at a low temperatures, which can be seen in the nanothermal profile measured by AFM. 
The absorbance at $3080 \mathrm{~cm}^{-1}$ is also plotted with the DMT modulus in Fig. 8 to compare changes in the chemical structure with those of the mechanical properties during thermal ageing.

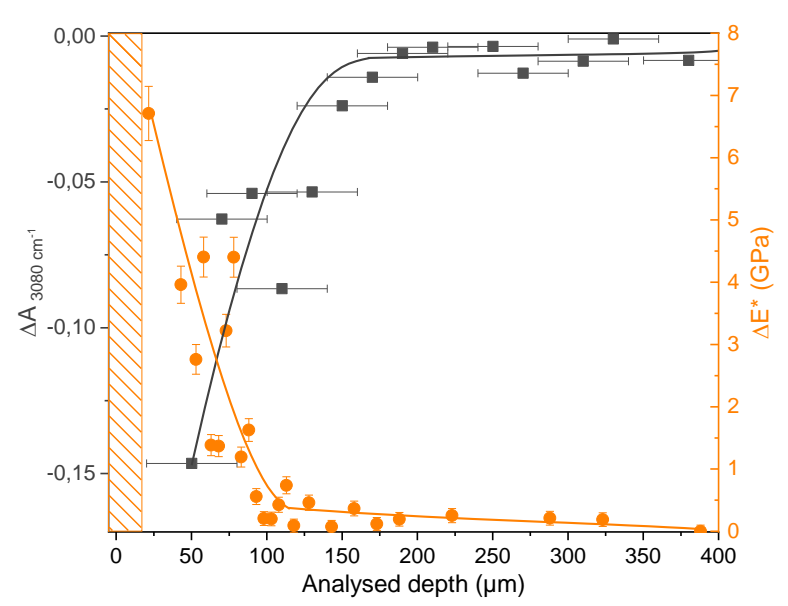

Fig. 8 Profile measured by micro-FTIR $(\square)$ and AFM peak force $(\Delta)$ of a sample thermoaged at $180{ }^{\circ} \mathrm{C}$ for $197 \mathrm{~h}$

Fig. 8 shows that the DMT modulus increases from the core to the surface, contrary to the absorption band that decreases at the same depth. The change in slopes occurs at a depth of approximately $125 \mu \mathrm{m}$. According to the thermo-oxidation mechanism, chain scissions occur at the $\mathrm{C}-\mathrm{N}$ bond of the amide group and thus lead to a decrease in this absorbance band. Previously, we found that chain scissions caused an increase in the crystallinity. As crystalline regions have higher mechanical properties than amorphous regions, this increase results in a rise in the stiffness, represented in this study by the DMT modulus.

In this article, the crystalline fraction was chosen as a simple factor to characterise the microstructure degradation, while the DMT modulus represents the mechanical properties. Fig. 9 compares the infrared and nanomechanical AFM profiles of a sample oxidised for 197 h at $180^{\circ} \mathrm{C}$. 


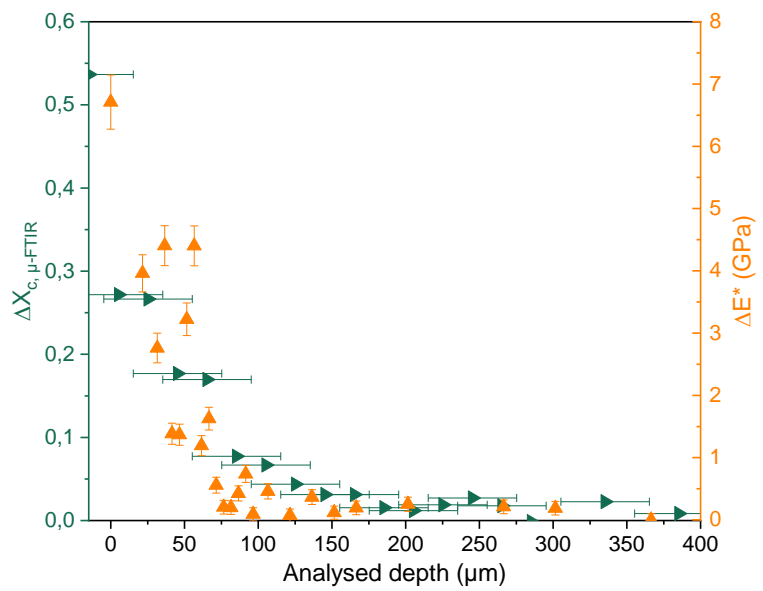

Fig. 9 Crystallinity gradient $(\checkmark)$ and AFM peak force $(\Delta)$ as a function of the thickness of a sample thermoaged at $180{ }^{\circ} \mathrm{C}$ for $197 \mathrm{~h}$

Fig. 9 compares the profiles of the crystallinity and DMT from the surface to the core (400 $\mu \mathrm{m}$ depth). This chart provides evidence of a correlation between the two profiles. Chain scissions that were previously correlated to a drop in the melting temperature cause an increase in the crystallinity. These parallel evolutions confirm a quantitative and direct correlation between the modification of the chemical structure and that of the mechanical properties. 


\section{Conclusion}

Oxidation depth profiles were obtained for PA 6,6 samples thermally aged from $140{ }^{\circ} \mathrm{C}$ to $200{ }^{\circ} \mathrm{C}$ at different times by measuring the distribution of imides. We show that PA 6,6 degradation is controlled by oxygen diffusion, resulting in a higher oxidation degree at the surface than in the bulk. The heterogeneity of the degradation is temperature dependent, which means that oxidation becomes more superficial when the temperature increases. FTIR results also show the existence of a crystallinity profile where the surface has a higher crystallinity than the core. Additionally, we have shown that changes in the thermal and mechanical properties as a function of sample thickness can be measured by AFM. The comparison of the chemical structure changes with the thermal and mechanical properties shows a good correlation. Finally, the results presented in this study clearly show that AFM is a convenient and complementary method for determining the oxidation depth profiles of polyamide 6,6 .

\section{Acknowledgements}

The authors wish to thank Schneider Electric and ANRT for financial support, and Dupont TM and Philippe Miniou for the sample preparation. 
$-10 \mu \mathrm{m}$

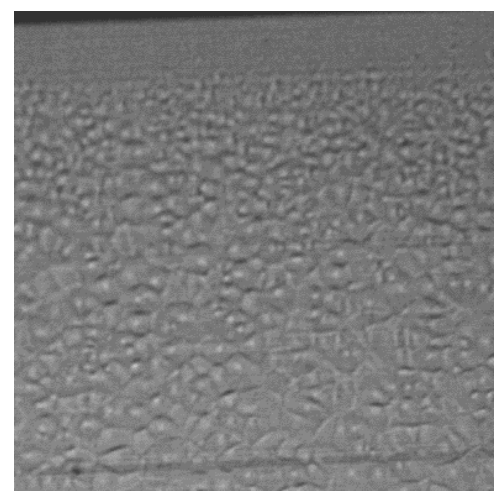

$-10 \mu \mathrm{m}$

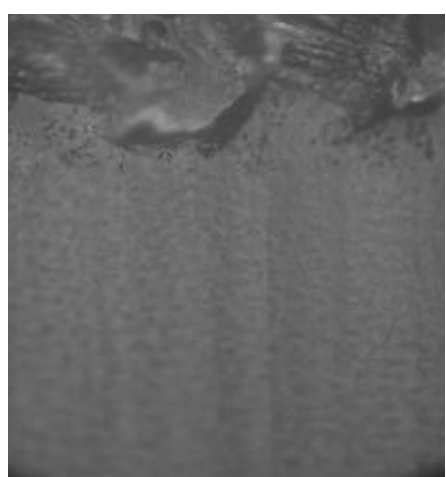

Figure 11: Pictures of samples: (left) before aging and (right) thermo-oxidised at $140{ }^{\circ} \mathrm{C}$ for 2000h.

\section{References}

[1] Shu Y, Ye L, Yang T. Study on the long-term thermal-oxidative aging behaviour of polyamide 6. J Appl Polym Sci 2008;110:945-957.

[2] Levchik SV, Weil ED, Lewin M. Thermal decomposition of aliphatic nylons. Polym Int 1999;48(67):532-57.

[3] Ksouri I, Haddar N. Long term ageing of polyamide 6 and polyamide 6 reinforced with $30 \%$ of glass fibers : temperature effect. J Polym Res 2018;25(153):1-12.

[4] Ksouri I, De Almeida O, Haddar N. Long term ageing of polyamide 6 and polyamide 6 reinforced with $30 \%$ of glass fibers: physicochemical, mechanical and morphological characteriZation. J Polym Res 2017;24(133):1-12.

[5] Grigg MN. Thermo-oxidative degradation of polyamide 6. PhD Thesis. Australia: Queensland University of Technology; 2006.

[6] Bolland JL. Kinetic studies in the chemistry of rubber and related materials. I. The thermal oxidation of ethyl linoleate. Proc R Soc 1946;1005:218-235.

[7] Sagar BF. Autoxidation of n-alkyl-amides. Part II. N-alkyl-amide hydroperoxides and diN-alkyl-amide peroxides. J Chem Soc Phys Org 1967:428-439. 
[8] Sagar BF. Autoxidation of n-alkyl amides. Part III. Mechanism of thermal oxidation. J Chem Soc Phys Org 1967; 1047-1061.

[9] Lánská B. Thermo-oxidation of lactam-based polyamides with carboxylic end groups. Decomposition of 6-hydroperoxy-6-hexanelactam in the presence of carboxylic acids. Eur Polym J 1994;30(2):197-204.

[10] Gijsman P, Tummers D, Janssen K. Differences and similarities in the thermooxidative degradation of polyamide 46 and 66. Polym Degrad Stab 1995;49:121125.

[11] Okamba-Diogo, Richaud E, Verdu J, Fernagut F, Guilment J, Fayolle B. Investigation of polyamide 11 embrittlement during oxidative degradation. Polymer 2016;82:49-56.

[12] Okamba-Diogo, Richaud E, Verdu J, Fernagut F, Guilment J, Fayolle B. Molecular and macromolecular structure changes in polyamide 11 during thermal oxidation. Polym Degrad Stab 2014;108:123-132.

[13] El-Mazry C, Ben Hassine M, Correc O, Colin X. Thermal oxidation kinetics of additive free polyamide 6-6. Polym Degrad Stab 2013;98:22-36.

[14] Jain A, Vijayan K. Effect of thermal ageing on nylon 6,6 fibres. J Mater Sci 2002;37:2623-2633.

[15] Pavlov NN, Kudryavtseva GA, Abramova IM, Vasileva VA, Zezina LA, Kazaryan LGK. Physical transformations and change in mechanical properties on thermal ageing of aliphatic polyamides. Polym Sci 1987;29(4):967-973.

[16] Forsstrom D, Terselius B.Thermo oxidative stability of polyamide 6 films. I. Mechanical and chemical characterization. Polym Degrad Stab 2000;67:69-78.

[17] Celina MC, Quintana A. Oxygen diffusivity and permeation through polymers at elevated temperature. Polymer 2018;150:326-342.

[18] Billingham NC, Walker T. Autoxidation of poly(4-methyl-pentene-1). I. The role of diffusion in autoxidation kinetics. J Polym Sci Polym Chem Ed 1975;13(5):1209-1222.

[19] Cunliffe AV, Davis A. Photo-oxidation of thick polymer samples- Part II: The influence of oxygen diffusion on the natural and artificial weathering of polyolefins. Polym Degrad Stab 1982;4(1):17-37. 
[20] Ono K, Kaeriyama A, Murakami K. Effects of diffusion in the oxidative degradation of vulcanized rubbers. I. Rate of chain scission in the steady state. J Polym Sci Polym Chem Ed 1975;13(11):2615-2620.

[21] Ono K, Kaeriyama A, Murakami K. Diffusion effects in the oxidative degradation of vulcanized rubbers. II. Transient rate of chain scission. J Polym Sci Polym Chem Ed 1978;16(7):1575-1586.

[22] Clough RL, Gillen KT. Oxygen diffusion effect in thermally aged elastomers. Polym Degrad Stab 1992;38(1):47-56.

[23] Celina MC. Review of polymer oxidation and its relationship with materials performance and lifetime prediction. Polym Degrad Stab 2013;98:2419-2429.

[24] Quintana A, Celina MC. Overview of DLO modelling and approaches to predict heterogeneous oxidative polymer degradation. Polymer Degrad Stab 2018;149:173-191.

[25] Celina MC, Wise J, Ottesen DK, Gillen KT, Clough RL. Correlation of chemical and mechanical property changes during oxidative degradation of neoprene. Polym Degrad Stab 2000;68(2):171-184.

[26] Mailhot B, Gardette JL. Polystyrene photooxidation. 2. A pseudo wavelength effect. Macromolecules 1992;25:4127-4133.

[27] Mailhot B, Bussière PO, Rivaton A, Morlat-Thérias S, Gardette JL. Depth profiling by AFM-nanoindentations and micro-FTIR spectroscopy for the study of polymer ageing. Macromol Rapid Comm 2004;25:436-440.

[28] Ablblad G, Stenberg B, Terselius B, Reitberger T. Imaging chemiluminescence instrument for the study of heterogeneous oxidation effects in polymers. Polym Test 1997;16:59-73.

[29] Celina MC, Wise J, Ottesen DK, Gillen KT, Clough RL. Oxidation profiles of thermally aged nitrile rubber. Polym Degrad Stab 1998;60(2-3):493-504.

[30] Celina MC, George GA. Heterogeneous and homogeneous kinetic analyses of the thermal oxidation of polypropylene. Polym Degrad Stab 1995;50(1):89-99.

[31] Larché JF, Bussière PO, Thérias S, Gardette JL. Photooxidation of polymers: Relating material properties to chemical changes. Polym Degrad Stab 2012;97:25-34. 
[32] Johnson LL, Eby RK, Meador MAB. Investigation of oxidation profile in PMR-15 polyimide using atomic force microscope (AFM). Polymer 2003;44:187-197.

[33] Mailhot B, Morlat-Thérias S, Bussière PO, Gardette JL. Study of the degradation of an epoxy/amine resin, 2 Kinetics and depth-profiles. Macromol Chem Phys 2005;206:585591.

[34] Mertz G, Hassouna F, Leclère P, Dahoun A, Toniazzo V, Ruch D. Correlation between (nano)-mechanical and chemical changes occurring during photo-oxidation of filled vulcanised styrene butadiene rubber (SBR). Polym Degrad Stab 2012;97(11):21952201.

[35] Larché JF, Bussière PO, Wong-Wah-Chung P, Gardette JL. Chemical structure evolution of acrylic-melamine thermoset upon photo-ageing. Eur Polym $\mathbf{J}$ 2012;48(1):172-182.

[36] Claudé B. Etude de la durabilité d'un système bicouche polymère utilisé pour le vitrage plastique. PhD Thesis. Clermont-Ferrand. 2002.

[37] Derjaguin BV, Muller VM, Toporov YP. Effect of contact deformation on the adhesion of particles. J Colloid Interface Sci 1975;53(2):314-326.

[38] Young TJ, Monclus MA, Burnett TL, Broughton WR, Ogin SL, Smith PA. The use of the PeakForce ${ }^{\mathrm{TM}}$ quantitative nanomechanical mapping AFM-based method for highresolution Young's modulus measurement of polymers. Meas Sci Technol 2011;22:1-6.

[39] Smolyakov G, Pruvost S, Cardoso L, Alonso B, Belamie E, Duchet-Rumeau J. AFM PeakForce QNM mode: Evidencing nanometre-scale mechanical properties of chitin-silica hybrid nanocomposites. Carbohydr Polym 2016;151:373-380.

[40] Coq Germanicus R, Mercier D, Agrebi F, Fèbvre M, Mariolle D, Descamps P, Leclère P. Quantitative mapping of high modulus materials at the nanoscale : comparative study between atomic force microscopy and nanoindentation. J Microsc 2020;280(1):51-62.

[41] Okamba-Diogo O, Richaud E, Verdu J, Fernagut F, Guilment J, Fayolle B. Molecular and macromolecular structure changes in polyamide 11 during thermal-oxidation Kinetic modelling. Polym Degrad Stab 2015;120:76-87. 
[42] Gijsman P, Dong W, Quintana A, Celina M. Influence of temperature and stabilization on oxygen diffusion limited oxidation profiles of polyamide 6. Polym Degrad Stab 2016;130:83-96.

[43] Ahlblad G, Forsström D, Stenberg B, Terselius B, Reitberger T, Svensson LS. Oxidation profiles of polyamide 6,6 studied by imaging chemiluminescence and FTIR. Polym Degrad Stab 1997;55:287-293.

[44] Audouin L, Langlois V, Verdu J. Role of oxygen diffusion in polymer ageing : kinetic and mechanical aspects. J Mater Sci 1994;29:569-583.

[45] Langlois V, Audouin L, Verdu J, Courtois P. Thermooxidative ageing of crosslinked linear polyethylene : Stabilizer consumption and lifetime prediction. Polym Degrad Stab 1993;40(3):399-409.

[46] Gillen KT, Clough RL. Rigorous experimental confirmation of a theoretical model for diffusion-limited oxidation. Polymer 1992;33:4358-4365.

[47] Wise J, Gillen KT, Clough RH. Quantitative model for the time development of diffusion-limited oxidation profiles. Polymer 1997;38:1929-1944.

[48] Sandeman I, Keller A. Crystallinity studies of polyamides by infrared, specific volume and X-ray methods. J Polym Sci 1956;19(93):401-435.

[49] Vasanthan N. Crystallinity determination of nylon 66 by density measurement and Fourier transform infrared (FTIR) spectroscopy. J Chem Educ 2012;89:387-390.

[50] Vasanthan N, Salem DR. Infrared spectroscopic characterization of oriented polyamide 66: Band assignment and crystallinity measurement. J Polym Sci Polym Phys 2000;38:516-524.

[51] Arimoto H. $\alpha-\gamma$ transition of nylon 6. J Polym Sci Gen Pap 1964;2(5):2283-2295.

[52] Murthy NS, Bray R, Curran S, McDonald M. A guide to material characterization and analysis. In: Sibilia J, editor. New-York: Wiley; 1994.

[53] Murty EM, Yehl TW. Adaptation of photoacoustic fourier transform infrared spectroscopy for studying the thermal oxidation of nylon 66 at $150^{\circ} \mathrm{C}$ correlated to mechanical properties. Polym Eng Sci 1990; 30(24):1595-1598. 
[54] Quintanilla L, Rodriguez-Cabello JC, Pastor JM. Structural analysis of injectionmoulded semicrystalline polymers by Fourier-transform infra-red spectroscopy with photoacoustic detection and differential scanning calorimetry: 2. Polyamide 6,6. Polymer 1994;35(11):2321-2328.

[55] Starkweather HW, Moynihan RE. Density, infrared absorption and crystallinity in 66 and 610 nylons. J Polym Sci 1956;22:363-368.

[56] Holland B, Hay J. Thermal degradation of nylon polymers. Polym Intern 2000;49(9):943-948.

[57] El Mazry C, Correc O, Colin X. A new kinetic model for predicting polyamide 6-6 hydrolysis and its mechanical embrittlement. Polym Degrad Stab 2012;97:1049-1059.

[58] Pliquet M, Rapeaux M, Delange F, Bussière PO, Therias S, Gardette JL. Multi-scales analysis of thermal degradation of polyamide 6,6: Correlating chemical structure to mechanical properties. Polym Degrad Stab 2021; 185: 109496.

[59] Murthy NS, Kagan VA, Bray RG. Effect of melt temperature and skin-core morphology on the mechanical performance of nylon 6. Polym Eng Sci 2002;42(5):940950.

[60] Spoerer Y, Androsch R, Jehnichen D, Kuehnert I. Process induced skin-core morphology in injection molded polyamide 66. Polymers 2020;12(4):894-902.

[61] Russell D, Beaumont PR. Structure and properties of injection-moulded nylon-6, Part 1: Structure and morphology of nylon-6. J Mater Sci 1980;15:197-207.

[62] Rhoades AM, Williams JL, Androsch R, Crystallization kinetics of polyamide 66 at processing-relevant cooling conditions and high supercooling. Thermochim Acta 2015;603:103-109.

[63] Gohn AM, Rhoades AM, Wonderling N, Tighe T, Androsch R. The effect of supercooling of the melt on the semicrystalline morphology of PA 66. Thermochim Acta 2017;655:313-318.

[64] Cavallo D, Gardella L, Alfonso GC, Portale G, Balzano L, Androsch R. Effect of cooling rate on the crystal/mesophase polymorphism of polyamide 6. Colloid Polym Sci 2011;289:1073-1079. 
[65] Drummer D, Meister S. Correlation of processing, inner structure, and part properties of injection moulded thin-wall parts on example of polyamide 66. Int J Polym Sci 2014;3:1-8.

[66] Forsström D, Terselius B. Thermo-oxidative stability of polyamide 6 films I. Mechanical and chemical characterisation. Polym Degrad Stab 2000;67:69-78.

[67] Rabello MS, White JR. Crystallization and melting behaviour of photo-degraded polypropylene - I. Chemi-crystallization. Polymer 1997;38:6379-6387.

[68] Spinu I, McKenna GB. Physical aging of nylon 66. Polym Eng Sci 1994;34(24):18081814.

[69] Mileva D, Androsch R, Radusch HJ. Effect of structure on light transmission in isotactic polypropylene and random propylene-1-butene copolymers. Polym Bull 2009;62:561-571.

[70] Marcellan A, Colomban P, Bunsell A. (Nano) structure, skin/core and tension behavior of polyamide fibres. J Raman Spectrosc 2004;35(4):308-315.

[71] Collin S, Bussière PO, Thérias S, Lambert JM, Perdereau J, Gardette JL. Physicochemical and mechanical impacts of photo-ageing on bisphenol A polycarbonate. Polym Degrad Stab 2012;97:2284-2293.

[72] Wu X, Shi S, Yu Z, Russell TP, Wang D. AFM nanomechanical mapping and nanothermal analysis reveal enhanced crystallization at the surface of a semicrystalline polymer. Polymer 2018;146:188-195.

[73] Nikiforov MP, Gam S, Jesse S, Composto RJ, Kalinin SV. Morphology mapping of phase-separated polymer films using nanothermal analysis. Macromol 2010;43:6724-6730

[74] Shu Y, Ye L, Yang T. Study on the long-term thermal-oxidative ageing behavior of polyamide 6. J Appl Sci 2008;110(2):945-957.

[75] Dokukin ME, Sokolov I. Quantitative mapping of the elastic modulus of soft materials with HarmoniX and PeakForce QNM AFM modes. Am Chem Soc 2012;28:16060-16071.

[76] Schön P, Bagdi K, Molnár K, Markus P, Pukánsky B, Vancso GJ. Quantitative mapping of elastic moduli at the nanoscale in phase separated polyurethanes by AFM. Eur Polym J 2011;47:692-698. 
[77] Sweers K, Van der Werf K, Bennink M, Subramaniam V. Nanomechanical properties of alpha-synuclein amyloid fibrils: a comparative study by nanoindentation harmonic force microscopy and PeakForce QNM. Nanoscale Res Lett 2011;6:270-280.

[78] Pittenger B, Erina N, Su C. A. Tiwari, editor. Mechanical property mapping at the nanoscale using PeakForce QNM scanning probe technique. Nanomechanical analysis of high performance materials. Dordrecht : Springer Science; 2014:31-51.

[79] Sharkey WH, Mochel WE. Mechanism of the photooxidation of amides. J Am Chem Soc 1959;81:3000-3005.

[80] Valk VG, Heidemann G, Dugal S, Krüssmann H. Konformationsabhängigkeit der reactivität $\mathrm{N}$-vicinaler methylengruppen in polyamiden. Angew Makromol Chem 1970;10(144):135-142. 